\title{
Grafen Oksit ve Deniz Kabuğu Takviyeli Polivinil Klorür Hibrit Kompozitlerin Karakterizasyonu
}

\author{
Meryem Göktaş $^{1 *}$, Ferda Mindivan ${ }^{2}$ \\ ${ }^{1}$ Bilecik Şeyh Edebali University Vocational School Gülümbe Campus, Bilecik (ORCID: 0000-0003-1583-8300), meryem.goktas@ @ilecik.edu.tr \\ ${ }^{2}$ Bilecik Şeyh Edebali University Department of Bioengineering Gülümbe Campus Bilecik (ORCID: 0000-0002-6046-2456) ferda.mindivan@ bilecik.edu.tr
}

(İlk Geliş Tarihi 19 Ağustos 2020 ve Kabul Tarihi 4 Kasım 2020)

(DOI: $10.31590 /$ ejosat.782828)

\begin{abstract}
ATIF/REFERENCE: Göktaş, M. \& Mindivan, F. (2020). Grafen Oksit ve Deniz Kabuğu Takviyeli Polivinil Klorür Hibrit Kompozitlerin Karakterizasyonu. Avrupa Bilim ve Teknoloji Dergisi, (20), 685-692.

$\ddot{O} \mathbf{z}$

Bu çalı̧̧mada hem grafen oksit (GO)'in üstün özelliklerinden yararlanmak hem de deniz kabuğunun geri dönüşümünü sağlamak için polivinil klorür (PVC) hibrit kompozitlerin üretilmesi ve yapısal özelliklerinin karakterize edilmesi amaçlanmıştır. Bu amaçla ağırlıkça (ağ.) \% 5, 10, 15 ve 20 öğ̈̈tülmüş deniz kabuğu tozları (DK) ve ağ. \% 0,1 dolgulu GO içeren hibrit kompozitler, kolloidal karıştırma yöntemi ile üretilmiştir. DK'nın XRF analizinde en yüksek oksit içeriğinin ağ. \% 98,53 oranıyla CaO olduğu belirlenmiştir. XRD analizinde düşük DK içeriğinde (ağ. \%5-\%10) hibrit kompozitlerin, tabakalar arası mesafe, kristal boyut ve mikro gerilme değerleri PVC-GO kompoziti ile benzer sonuçlar göstermiştir. Yüksek DK içerikli (ağ. \% 15 ve \% 20) hibrit kompozitlerin XRD paternleri, kalsit ve aragonit faz piklerinin dışında grafen pikinin gözlenmediğini göstermiştir. Sonuç olarak, yüksek DK içeriği, grafenin PVC matrisinde başarıyla eksfoliye olmasına sebep olmuştur. \%20 DK içeriğinde, DK ve GO'nun çekirdeklenme merkezleri olarak davranması, PVC-GO/DK\%20 hibrit kompozitinin en yüksek kristal boyut değerine ve en düşük mikro gerilme değerine sahip olmasına neden olmuştur. FTIR analiz sonuçları, hibrit kompozitlerde baskın kristal formunun aragonit olduğunu doğrulamıştır. SEM ve EDX analizleri, DK ve GO'nun PVC polimer matrisinde homojen dağılımlarını ve hibrit kompozitlerin pürüzsüz yüzey görüntülerini sunmuştur.
\end{abstract}

Anahtar Kelimeler: PVC, Hibrit kompozit, Grafen oksit, Deniz kabuğu, Karakterizasyon.

\section{Characterization of Graphene Oxide and Sea Shell Reinforced Polyvinyl Chloride Hybrid Composites}

\begin{abstract}
In this study, it was aimed to produce polyvinyl chloride (PVC) hybrid composites in order to utility from the excellent properties of graphene oxide (GO) and to recycle sea shell and to characterize their structural properties. For this purpose, the hybrid composites containing 5, 10, 15 and $20 \mathrm{wt} . \%$ of milled sea shell powders (DK) and $0.1 \mathrm{wt} . \%$ of GO filled were fabricated by colloidal blending method. In the XRF analysis of DK, it was determined that the highest oxide content was calcium oxide (CaO) 98.53 wt.\%. According to XRD analysis, hybrid composites with low DK content (5 wt.\%-10 wt.\%) showed similar results with interlayer distance, crystallite size and micro strain values of PVC-GO composite. XRD patterns of the hybrid composites with high DK content (15 wt.\% and $20 \mathrm{wt} . \%)$ showed that graphene peak was not observed except calcite and aragonite phase peaks. As a result, the high DK content caused to exfoliate of graphene in the PVC matrix successfully. DK and GO acted as nucleation centers at 20 wt.\% DK content and therefore PVC-GO/DK20\% hybrid composite had the highest crystal size and the lowest micro-stress values. FTIR analysis results confirmed that aragonite was the dominant crystal form in the hybrid composites. SEM and EDX analyzes had presented homogeneous distributions of DK and GO in PVC polymer matrix and smooth surface images of hybrid composites.
\end{abstract}

Keywords: PVC, Hybrid composite, Graphene oxide, Sea shell, Characterization.

\footnotetext{
"Sorumlu Yazar: meryem.goktas@ @ilecik.edu.tr
} 


\section{Giriş}

Hibrit kompozit malzemeler; malzeme bilimi teknolojisinin tüm alanlarında, üretim teknikleri ve teorik araştırmalarda büyük ilgi görmektedir. Takviye ve dolgu malzemelerinin ilavesi ile üretilen polimer matrisli hibrit kompozitlerin özelliklerinin belirlenmesine yönelik araştırmalar devam etmektedir [1].

Polivinil klorür (PVC) matrisli hibrit kompozitler, dikkat çeken hibrit biyokompozit malzemeler arasındadır [2-4]. PVC hibrit kompozitlerini üretmek için buğday kabuğu, buğday samanı, pirinç kabuğu vb. [5], takviye malzemeleri olarak kullanılmıştır. Bunlar arasında pirinç lifleri potansiyel takviyelerden biri olarak kabul edilmiştir [6]. Kalsiyum karbonat $\left(\mathrm{CaCO}_{3}\right)$, düşük maliyetli inorganik bir takviye malzemesidir. Literatürde $\mathrm{PVC}$ matrisinde $\mathrm{CaCO}_{3}$ ' ün takviye malzemesi olarak kullanıldığı bir çalışmaya rastlanmıştır. Bu çalışmada yüksek oranda $\mathrm{CaCO}_{3}$ içeren öğütülmüş deniz kabuğu tozları (DK) takviye malzemesi olarak seçilmiştir. Deniz kabuğu \%1-5 oranında çevreye ve insan sağlığına zararlı gazlar içeren organik maddelerden oluşmaktadır. Bu yüzden hem deniz kabuğunun zararlı etkilerini gidermek hem de geri dönüşümünü sağlamak için $\mathrm{CaCO}_{3}$ kaynağı olarak bu çalışmada DK kullanılmıştır. Son yıllarda grafen ve türevlerinin, üstün özelliklerinin (termal iletkenlik, üstün mekanik ve elektronik özellikler, büyük yüzey alanı) yanı sıra ucuz bir dolgu maddesi olarak kompozit malzemelerde kullanımı dikkat çekmektedir [7, 8]. Doğada bol miktarda bulunan grafit, Hummers yöntemi ile GO sentezinde kullanılmaktadır [8]. GO, oksitlenmiş bir grafen tabakası olup, epoksi, hidroksil, karbonil ve karboksil içeren oksijenli fonksiyonel gruplara sahiptir [9]. Grafen türevleri içerisinde özellikle GO, kolay sentezi, geniş yüzey alanı ve antibakteriyel özellikleri nedeniyle kompozit uygulamaları için yaygın olarak kullanılan bir dolgu maddesidir. $\mathrm{Bu}$ çalışmada ise; yüksek oranda $\mathrm{CaCO}_{3}$ içeren $\mathrm{DK}$ takviye malzemesi olarak, $\mathrm{GO}$ ise dolgu malzemesi olarak seçilip PVC hibrit-kompozitleri kolloidal karıştırma yöntemiyle üretilmiş ve yapısal özellikleri değişen ağ. \% DK oranlarında incelenmiştir. Tüm hibrit kompozitlerin yapısal karaakterizasyonu yalnızca GO içeren PVC/GO kompozitinin özellikleri ile karşılaştırılmıştır.

\section{Materyal ve Metot}

\subsection{Yöntem ve Karakterizasyon}

Bu çalışmada kullanılan deniz kabuğu örnekleri Bulgaristan/Varna Karadeniz kıyısından toplanıp, yıkanmıştır. Öğütülmeden önce 36 saat boyunca $70^{\circ} \mathrm{C}^{\prime}$ de etüvde kurutulmuştur. Kurutulan deniz kabuğu örnekleri elekli (Fritsch, Analysette 3) Fritsch- Pulverisette 9, GmbH marka değirmen de öğütülüp elde edilen DK temiz bir kapta saklanmıştır. Deniz kabuklarından DK eldesi için izlenen yol ise Şekil 1'de gösterilmiştir.

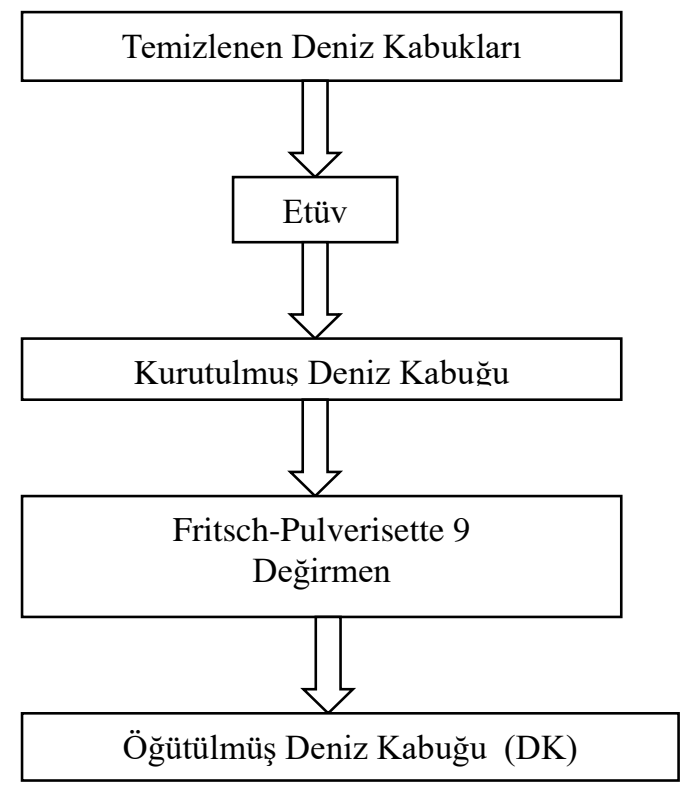

Şekil 1. DK Eldesi.

GO, Hummers yöntemi ile grafit tozundan sentezlenmiştir [9]. Grafit ( $1 \mathrm{~g}) 69 \mathrm{~mL} \mathrm{H} \mathrm{SO}_{4}$ ile muamele edilmiş ve karışım bir buz banyosunda yaklaşık 30 dakika karıştırılmıştır. Grafitin çözelti içinde homojen dağılmasından sonra çözeltiye $\mathrm{KMnO}_{4}(8$ g) yavaş yavaş ilave edilmiş ve elde edilen karışım 15 dakika daha karıştırılmıştır. Daha sonra karışım buz banyosundan çıkarılmış ve bir gece boyunca $35^{\circ} \mathrm{C}$ de karıştırılmıştır. Daha sonra karışıma yavaşça $70 \mathrm{~mL}$ saf su ilave edilerek çözelti 2 saat kuvvetli karıştırılmıştır. $12 \mathrm{~mL} \% 30 \mathrm{H}_{2} \mathrm{O}_{2}$ ilave edildikten sonra karışımın rengi altın sarısına dönüşmüştür. Karışım birkaç kez \%3'lük HC1 ve DI su ile yıkanarak süzülmüştür ve $65^{\circ} \mathrm{C}^{\prime} \mathrm{de}$ etüvde 12 saat süreyle kurutulmuştur.
DK takviyeli PVC-GO hibrit kompozitleri kolloidal karıştırma yöntemi ile hazırlanmıştır. $10 \mathrm{~g}$ PVC $60-70^{\circ} \mathrm{C}^{\prime} \mathrm{de}$ tetrahidrofuran (THF) içerisinde çözülmüştür. A $\breve{g}$. \%0,1 GO içeren hibrit kompozitleri hazırlamak için ayrı bir kapta $25 \mathrm{ml}$ THF içirisinde GO sonike edilmiştir. Daha sonra ayrı ayrı THF içerisinde çözünen PVC çözeltisi ve dağıtılan GO kolloid çözeltisi birbirleri ile karıştırılmıştır. Farklı ağ. \% DK tozları PVC-GO karışımına ilave edilip, önce ultrasonik banyoda 30 dakika bekletilip, daha sonra manyetik karıştırıcıda 1 saat boyunca karıştırılmıştır. Tüm karışım, THF buharlaşana kadar manyetik karıştırıcıda karıştırılmaya devam edilmiştir. Homojen hibrit-kompozit karışımlar, cam petri kabına dökülüp, hibritkompozitlerin elde edilmesi için etüv de $60-70^{\circ} \mathrm{C}^{\prime}$ de 
kurutulmuştur. Tüm hibrit kompozitlerin karşılaştırıldı ̆̆ PVC/GO kompoziti de yukarıda izah edilen kolloidal karıştırma yöntemi ile üretilmiştir. Hazırlanan GO dolgu ve DK takviye ağ. oranları ve hibrit-kompozit kodları Tablo 1' de verilmiştir.

Tablol. GO Dolgu ve DK Takviye Ăg. Oranlarl ve Hibrit-Kompozit Kodlart

\begin{tabular}{|c|c|c|}
\hline Hibrit-kompozit kodları & GO içeriği (Ă̆g. \%) & DK içeriği (Ă̆. \%) \\
\hline PVC-GO & 0,1 & - \\
\hline PVC-GO/ DK\% 5 & 0,1 & 5,0 \\
\hline PVC-GO/ DK\%10 & 0,1 & 10,0 \\
\hline PVC-GO/ DK\% 15 & 0,1 & 15,0 \\
\hline PVC-GO/DK\% 20 & 0,1 & 20,0 \\
\hline
\end{tabular}

\section{Araştırma Sonuçları ve Tartışma}

DK kimyasal bileşimi, X-1şını floresans spektroskopisi (XRF) (Panalitik-Axios) ile belirlenmiştir. Üretilen hibritkompozitlerin kristal yapısı ve PVC matrisinde dolgu ve takviye malzemelerinin dağılımları X-1şını difraksiyonu (XRD) ile analiz edilmiştir. Tüm XRD analizleri, $2 \theta^{\circ}=5-55^{\circ}$ aralığında $\mathrm{Cu}$ $\mathrm{K} \alpha$ ' lı bir PAN analitik marka difraktometre kullanılarak elde edilmiştir. Hibrit-kompozitlerin yapısında bulunan dolgu ve takviye malzemelerinin polimer matriks ile etkileşimini belirlemek için yapılan Fourier Dönüşümlü Kızılötesi Spektroskopi (FTIR) analizi için Spectrum 100, Perkin Elmer marka cihaz kullanılarak $4000-400 \mathrm{~cm}^{-1}$ dalga sayısı aralığında analizler gerçekleştirilmiştir. Kompozitlerin yüzey özelliklerini gözlemlemek ve dolgu-takviye malzemelerinin matrikste dağılımını incelemek için Zeiss Supra 40 VP marka taramalı taramalı elektron mikroskobu (SEM) ve bu mikroskoba bağlı Enerji Dağılımlı X-Işını (EDX) hibrit-kompozitlerin elementel haritalama analizleri için kullanılmıştır.

\subsection{XRF Analizi}

DK örneklerinin XRF analiz sonuçları Tablo 2'de verilmiştir. Çalışmada kullanılan DK örneklerinin XRF analizlerine bakıldığında, ağ. \% 98,53 $\mathrm{CaO}$ ve $\% 0,573 \mathrm{P}_{2} \mathrm{O}_{5}, \%$ $0,447 \mathrm{~K}_{2} \mathrm{O}, \% \quad 0,139 \mathrm{MgO}$ ve \% $0,111 \mathrm{SiO}_{2}$ içeriğine sahip olduğu görülmüştür (Tablo 2). Geri kalan ağ. \% değerleri ise diğer oksitlerin oluşturduğu saptanmıştır. Fombuena ve ark. [10] ve Moustafa ve ark. [11], deniz kabuğunun yüksek miktarda $\mathrm{CaCO}_{3}$ ' dan oluştuğunu rapor etmişlerdir. Tablo 2'de verilen XRF analiz sonuçlarında ki \% $\mathrm{CaO}$ içeriği, $\mathrm{CaCO}_{3}$ bazlı DK numunelerinin hibrit-kompozit uygulamaları için uygun bir takviye malzemesi olduğunu göstermiştir.

Tablo 2. DK Numunelerinin Bileşimi (\% Oksit)

\begin{tabular}{cc}
\hline Oksit & Ăg. \% \\
\hline $\mathrm{CaO}$ & 98,531 \\
$\mathrm{P}_{2} \mathrm{O}_{5}$ & 0,573 \\
$\mathrm{~K}_{2} \mathrm{O}$ & 0,447 \\
$\mathrm{MgO}$ & 0,139 \\
$\mathrm{SiO}_{2}$ & 0,111 \\
$\mathrm{Cl}$ & 0,010 \\
$\mathrm{Fe}_{2} \mathrm{O}_{3}$ & 0,066 \\
$\mathrm{Al}_{2} \mathrm{O}_{3}$ & 0,049 \\
$\mathrm{SrO}_{\mathrm{SO}}$ & 0,043 \\
$\mathrm{NiO}$ & 0,018 \\
\hline
\end{tabular}

\subsection{XRD Analizi}

PVC-GO kompozitinin ve PVC-GO/DK hibrit kompozitlerinin kristal yapıları XRD analizi ile belirlenmiştir (Şekil 2 ve 3). Şekil 2'de PVC-GO kompoziti XRD paterninden anlaşılacağ1 gibi amorf bir yapı sergilemiştir. Ancak $2 \theta^{\circ}$ $=9.95^{\circ}$ 'de GO'ya ait zayıf bir pik gözlenmiştir. Şekil 3 'de hibrit kompozitlerin XRD paternlerinden elde edilen pikler DK' nın aragonit ve kalsit fazlarını temsil etmektedirler. XRD paterninde görülen en şiddetli piklerin $2 \theta=26.60^{\circ}, 33.60^{\circ}$ ve $46.31^{\circ}$ 'deki $\mathrm{CaCO}_{3}$ 'a ait aragonit yapısıyla ilişkili olduğu bilinmektedir [1215]. Şekil $3^{\prime}$ deki $2 \theta=26.60^{\circ}, 27.78^{\circ}, 33.60^{\circ}, 36.60^{\circ}, 37.94^{\circ}$, $38.38^{\circ}, 41.76^{\circ}, 46.31^{\circ}, 48.97^{\circ}, 50.79^{\circ}, 53.00^{\circ}$, ve $53.57^{\circ}$ de tepe noktaları sırasıly DK'nın aragonit fazına, $39.19^{\circ}$ ve $43.45^{\circ}$ 'deki pikler ise DK'nın kalsit fazına karşılık gelmektedir [16-18]. Şekil 3'de görüldüğü gibi yapının büyük çoğunluğunun aragonit fazına ait olduğu belirlenmiştir. Bu fazın miktarı bu çalışma için oldukça önemlidir, çünkü aragonit $\mathrm{CaCO}_{3}$ mineralinin diğer 
polimorfları (kalsit ve vaterit) arasında en biyo-uyumlu özelliklere sahip olan faz olarak bilinmektedir [19]. Ayrıca ağ. $\% 5$ ve $\% 10$ DK ilave edilmiş hibrit-kompozitlerin XRD paterninde grafene ait $2 \theta^{\circ}=9.95^{\circ}$ de geniş ve zayıf karakteristik pikler görülmektedir. Ancak ağ. \% 15 ve \%20 DK ilave edilmiş hibrit-kompozitlerin XRD paternlerine bakıldığında kalsit ve aragonit piklerinin dışında grafene ait herhangi bir pik gözlenmemiştir. $\mathrm{Bu}$ durum yüksek $\mathrm{DK}$ ilavelerinde, grafenin PVC matriksinde başarılı şekilde eksfoliye olduğunu göstermiştir. Bir başka deyişle; GO’ nun sahip olduğu karboksil $(\mathrm{COOH})$, karbonil $(-\mathrm{C}=\mathrm{O})$, epoksi $(\mathrm{C}-\mathrm{O}-\mathrm{C})$ ve hidroksil $(-\mathrm{OH})$ gibi oksijen içeren fonksiyonel gruplar, GO hidrasyonunu geliştirmiş ve polimer matrisinde eksfoliasyona sebep olmuştur $[20,21]$.

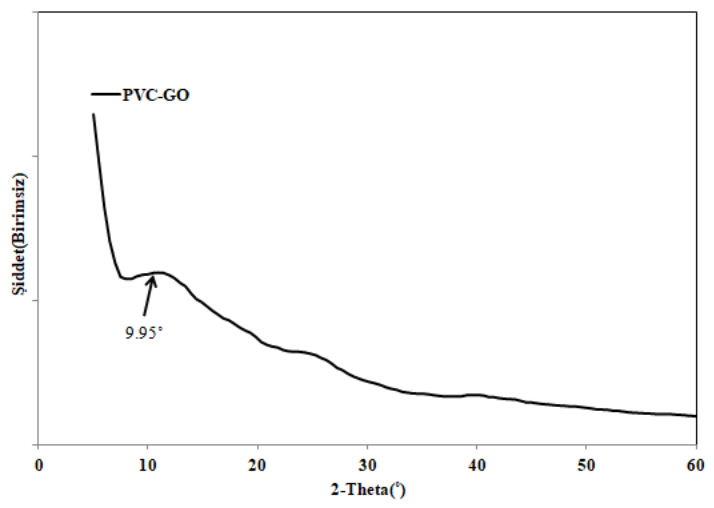

Şekil 2. PVC-GO Kompozitin XRD Paterni.

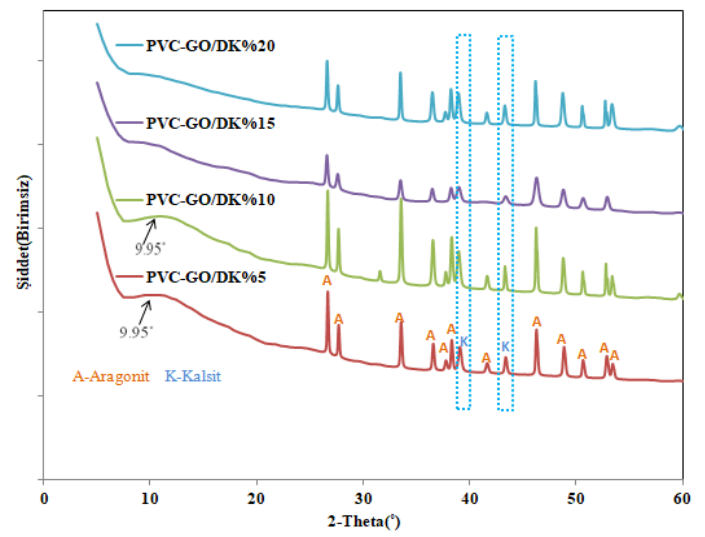

Şekil 3. PVC-GO/DK Hibrit-Kompozitlerin XRD Paternleri.

Farklı ağ.\% DK içeriğine sahip hibrit-kompozitlerin tabakalar arası mesafe, kristal boyut ve mikro gerilme değerleri Tablo 3 'te verilmiştir. Tablo 3 incelendiğinde tabakalar arasi mesafe değerleri PVC-GO kompozit ve PVC-GO/DK hibritkompozitlerinde benzer sonuçlar vermiştir. Kompozitlerin kristal boyut değerleri kıyaslandığında PVC-GO, PVC-GO/DK\%5, PVC-GO/DK\%10 kompozitlerinin kristal boyut değerleri $(\AA ̊)$ aynı iken, PVC-GO kompoziti ile karşılaştırıldığında. PVCGO/DK\%15 hibrit kompozitinde \% 43.63 azalma, PVC-GO/ DK\%20 hibrit kompozitinde ise $\% 25.85$ artış görülmüştür. $\mathrm{Bu}$ artış ve azalma aşağıdaki Eşitlik (1) kullanılarak hesaplanmıştır $[22,23]$. karışımı)

$\operatorname{Hc}(\%)=100 x[\mathrm{I}($ karışım $)-$ I (kontrol karışımı) $]$ / I (kontrol (1)

Burada Hc, kristal bileşiminin \% artışı veya azalma değerlerini vermektedir. I (karışım) ve I (kontrol karışımı) spesifik kristal fazına uygun kontrol karışımı yoğunluklarını temsil etmektedir.
PVC-GO ve düşük içerikte DK içeren (\%5-\%10) hibrit kompozitlerin mikro gerilme değerleri benzer sonuçlar vermiştir. PVC-GO/DK\%15 hibrit-kompoziti en düşük, PVC-GO/DK\%20 hibrit kompoziti ise en yüksek mikro gerilme değerine sahip olmuştur. Tüm bu sonuçlar düşük miktarda DK ilavesinin yapıda önemli bir değişim yaratmadığını, yüksek DK ilavesinin ise hem GO' nun dağılımında hem de yapının kristal boyut ve mikro gerilme değerlerinde etkili olduğunu göstermiştir. En düşük kristal boyut değerine sahip olan PVC-GO/DK\%15 hibrit kompozitinde $\% 15$ DK ilavesinin polimer zincirlerini bağlayarak zincir düzeninde bir bozulma etkisi yaratarak mikro gerilme değerlerinde de artışa neden olmuştur. \%20 DK içeriğinde, DK ve GO, çekirdeklenme merkezleri olarak davrandığ düşünüldüğünden, PVC-GO/DK\%20 hibrit kompoziti en yüksek kristal boyut değerine ve en düşük mikro gerilme değerine sahip olmuştur. Amangah ve ark.[24] yapmış oldukları çalışmalarda benzer sonuçlar bulmuşlardır. Grafen/polisülfid polimer nanokompozitlerin özellikleri üzerine grafen nanoplatelets etkisini araştırdıkları çalışmada XRD analizi ile nanokompozitlerin kristalliği üzerine dolgu maddesinin etkisi incelenmiştir. Elde edilen nanokompozitlerin kristal boyut değerinin, ağ. \% 0,7' ye kadar grafen ilavesinde arttığı sonucuna 
varılmıștır. Bununla birlikte, daha fazla GO ilavesinde nanoplateletslerin polimer matriksin yüzeyine bağlanmasının yanında, kristalleşme işlemi sırasında zincir yapısında yeniden yapılanmaya neden olduğu sonucuna varılmıştır [24].

Tablo 3. PVC-GO Kompozit ve PVC-GO/DK Hibrit-Kompozitlerin $2 \theta^{\circ}=\sim 33.55^{\circ}$ de Hesaplanan Ortalama Tabakalar Arası Mesafe (A), Kristal Boyut (A) ve Mikro Gerilme (\%) Değerleri

\begin{tabular}{cccc}
\hline $\begin{array}{c}\text { Hibrit-Kompozit } \\
\text { Kodları }\end{array}$ & $\begin{array}{c}\text { Tabakalar Arası } \\
\text { Mesafe }(\AA)\end{array}$ & Kristal Boyut (̊̊) & Mikro Gerilme (\%) \\
\hline PVC-GO & 2,67019 & 669,3700 & \\
PVC-GO/ DK\%5 & 2,67019 & 669,3838 & 0,199870 \\
PVC-GO/ DK\%10 & 2,67047 & 669,3777 & 0,199452 \\
PVC-GO/ DK\%15 & 2,67515 & 377,3495 & 0,199474 \\
PVC-GO/DK\% 20 & 2,67486 & 842,4129 & 0,354465 \\
\hline
\end{tabular}

\subsection{FTIR Analizi}

PVC-GO kompozitinin ve PVC-GO/DK hibrit kompozitlerinin FTIR spektrumları Şekil 4'de verilmiştir. Şekil 4'de PVC-GO kompozitler için 2911-2859, 1426, 1252, 956 ve $834 \mathrm{~cm}^{-1}$, deki dalga sayısına sahip pikler sırasıyla $\mathrm{C}-\mathrm{H}$ gerilme ve titreşim, $\mathrm{CH}_{2}$ gerilme, $\mathrm{CH}$-sallanma, trans sallama $\mathrm{CH}$ ve $\mathrm{C}-\mathrm{Cl}$ gerilme pikine atfedilmiştir [25]. Hibritkompozitlerin FTIR spektrumlarında, PVC-GO/DK\%5 hibrit kompozitinde $3680 \mathrm{~cm}^{-1}$, deki geniş pik $\mathrm{OH}$ gruplarının gerilme titreşimine atfedilmiştir [26]. DK içeriği arttıkça pik şiddeti giderek azalmış \%20 DK içeriğinde tamamen kaybolmuştur. Bu durum artan DK içeriğinin polimer matrisi ile etkileşimden kaynaklanmıştır. \%20 DK içeren hibrit kompozit hariç tüm hibrit-kompozitler için, karakteristik $\mathrm{C}=\mathrm{O}$ (Amid) gerilme titreşim piki $1726 \mathrm{~cm}^{-1}$, de gözlenmiştir [27]. Bu sonuç en yüksek DK içeriğinin amid grubu gerilme titreşimini ciddi oranda etkilediğini göstermiştir. Tüm hibrit kompozitlerde 1425 $\mathrm{cm}^{-1}$, deki pik karbonat iyonunun asimetrik gerilme titreşimini göstermiştir [28]. Ayrıca, 1097, 853 ve $698 \mathrm{~cm}^{-1}$ civarındaki pikler, sırasıyla simetrik karbonat gerilme titreşimine, aragonitin dış ve iç düzlem bükülme titreşim piklerine karşılık gelmiştir $[29,30]$. Sonuç olarak, FTIR analiziyle kalsiyum karbonatın aragonit fazının baskın olduğu anlaşılmıştır.

\subsection{SEM ve EDX Analizi}

Şekil 4. PVC-GO kompoziti ve PVC-GO/DK Hibrit-Kompozitlerinin FTIR Spektrumları.

Hazirlanan PVC-GO kompozitinin ve PVC-GO/DK hibritkompozitlerin SEM görüntüleri Şekil 5'te ve EDX elementel haritalama analizleri ise Şekil 6'da verilmiştir. SEM görüntüleri incelendiğinde, PVC-GO kompozitinin yüzey morfolojisinin tamamen pürüzsüz olduğu görülmektedir (Şekil 5). Daha önce PVC/GO kompoziti üzerine yapılan bir çalışmada düşük miktarda GO (ağ. \% 0,1) eklenerek elde edilen PVC kompozitin SEM görüntüsü, PVC ile GO arasında sağlanan uyum neticesinde pürüzsüz bir yüzey morfolojisini sunmuştur [25].
PVC-GO/DK\%5 hibrit kompozitin Şekil 5'deki SEM görüntülerinden pürüzlü ve düzensiz bir yüzeye sahip olduğu, PVC-GO/DK\%10 hibrit-kompozitin yüzeyinde ise çok sayıda küçük ve düzensiz DK parçacıklarının varlığı gözlemlenmiş ve bu hibrit-kompozitin yüzey dokusunun diğer kompozitlerle karşılaştırıldığında nispeten pürüzsüz olduğu görülmüştür. SEM görüntülerinden, PVC-GO/DK\%15 ve PVC-GO/DK\%20 hibritkompozitlerinin ise yüzey morfolojisinde belirgin farklılıklar gözlenmemiştir. $\mathrm{Bu}$ kompozitlerin, küçük parçacıklar ile heterojen yüzey morfolojisine sahip olduğu SEM görüntülerinde görülebilmektedir (Şekil 5). 

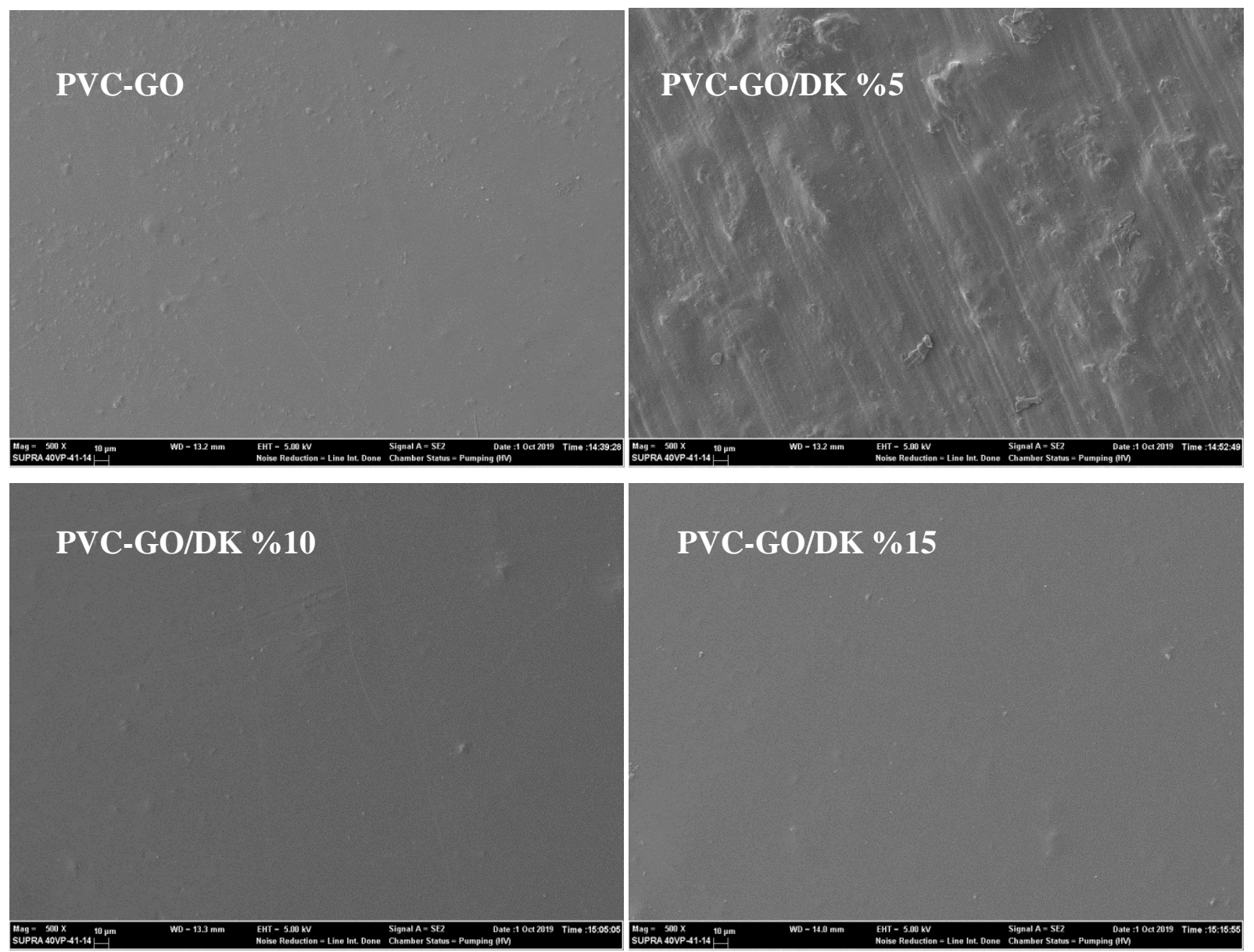

PVC-GO/DK \% 20

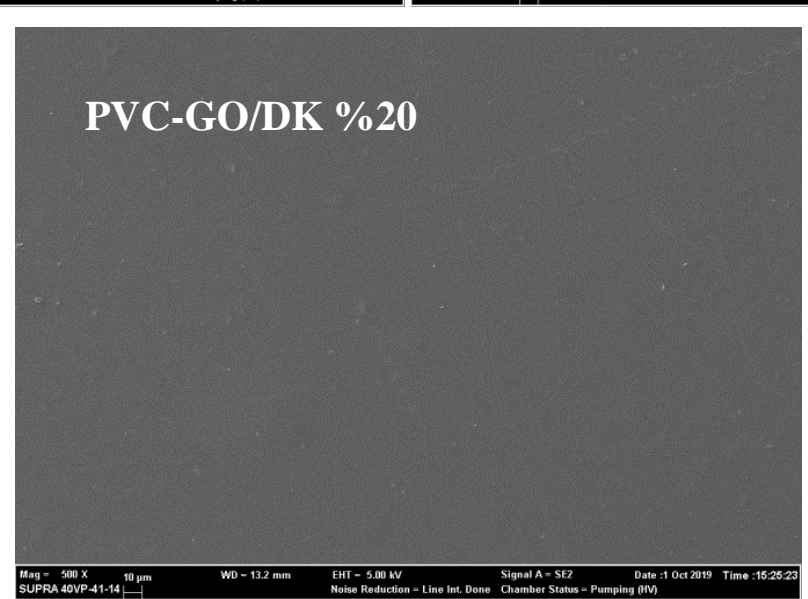

Şekil 5. PVC-GO kompoziti ve PVC-GO/DK hibrit-kompozitlerinin SEM görüntüleri (500 X).

PVC matrisinde GO ve DK dağılımının ayırt edilmesi için EDX analizi tercih edilmiştir. Şekil 6'da EDX analizinde tüm hibrit-kompozitler için ana elementler $(\mathrm{Cl}, \mathrm{O}, \mathrm{Ca}$ ve $\mathrm{Si})$ seçilmiş̧ir. PVC-GO kompozitinin EDX sonuçlarına bakıldığında, büyük miktarda oksijen içeren fonksiyonel gruplara sahip GO' nun belli bölgelerde toplanmadan PVC matriksinde homojen şekilde dağıldığı görülmektedir. Tüm PVC-GO/DK hibrit-kompozitlerin EDX haritalarına bakıldığında $\mathrm{Cl}, \mathrm{O}, \mathrm{Ca}$ ve $\mathrm{Si}$ elementlerinin dağılımının homojen olduğu görülmektedir. 


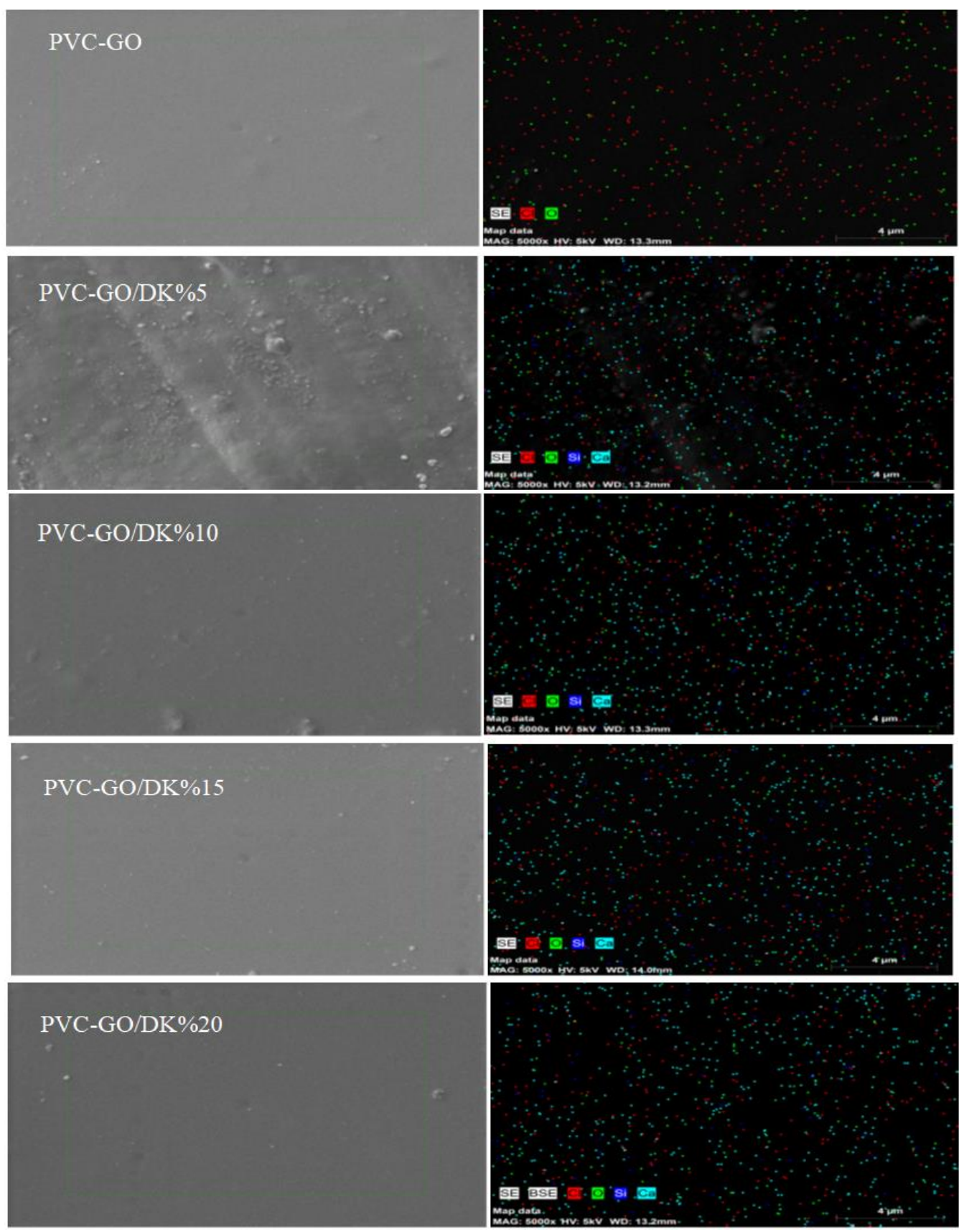

Şekil 6. PVC-GO kompoziti ve PVC-GO/DK Hibrit-Kompozitlerinin EDX Elementel Haritalaması.

\section{Sonuç}

$\mathrm{Bu}$ çalışmada $\mathrm{PVC}^{\prime}$ nin matris olarak, GO'nun dolgu ve DK'nın takviye fazı olarak seçilerek kolloidal karıştırma yöntemiyle hibrit kompozit üretimi yapılmıştır. DK'nın polimer matriste değişen ağ. \% değerlerinin üretilen hibrit kompozitlerin yapısal özellikleri üzerine etkisi $\mathrm{PVC} / \mathrm{GO}$ kompoziti ile karşılaştırılarak incelenmiştir. XRF analiz sonuçlarından DK' nın en yüksek kimyasal bileşiminin ( $\%$ oksit) $\mathrm{CaO}$ olduğu belirlenmiştir. XRD analiz sonuçları ise GO dolgusu ve DK takviyesinin yüksek DK içeriğinde (\%15-20) polimer matrisde düşük DK içeriğine göre (\%5-10) daha iyi etkileşim sağlayarak dolgu ve takviye fazlarının polimer matriste daha homojen dağıldığını göstermiştir. Ayrıca hibrit-kompozitlerin tabakalar e-ISSN: 2148-2683 aras1 mesafe, kristal boyut ve mikro gerilme değerlerine bakıldığında düşük miktarda DK ilavesinin (\%5-10) yapıda önemli bir değişim yaratmadığı, yüksek DK ilavesinin (\%15-20) ise hem GO' nun dağılımında hem de yapının kristal boyut ve mikro gerilme değerlerinde etkili olduğu sonucu ortaya çıkmıştır. Ayrıca \%20 DK içeriğinde, DK ve GO, çekirdeklenme merkezleri olarak davranı, PVC-GO/DK\%20 hibrit kompoziti en yüksek kristal boyut değerine ve en düşük mikro gerilme değerine sahip olmuştur. FTIR analiz sonuçları ise, DK örneğinde baskın kristal formunun aragonit olduğunu doğrulamıştır. Bununla birlikte SEM ve EDX analizleri, DK ve GO'nun polimer matriste homojen dağılımlarını ve pürüzsüz yüzey görüntülerini ortaya çıkarmıştır. 


\section{Teşekkür}

Hazırlanan bu çalışma Bilecik Şeyh Edebali Üniversitesi tarafindan desteklenen 2019-02.BŞEÜ.11-01 nolu Bilimsel araştırma projesinden türetilmiştir.

\section{Kaynakça}

1. Kim. S., Hee Ku, S., Yoon Lim, S., Hong Kim, J. \& Beum Park, C. (2011). Graphene-Biomineral Hybrid Materials. Adv. Mater., 23, 2009-2014. DOI: https://doi.org/10.1002/adma.201100010.

2. Bagherinia, M.A., Sheydaei, M. \& Giahi, M. (2017). Graphene oxide as a compatibilizer for polyvinyl chloride/rice straw composites. J Polym Eng, 37(7),661-70. DOI: https://doi.org/10.1515/polyeng-2016-0249.

3. Croitoru, C., Spirchez, C., Cristea, D., Lunguleasa, A., Pop, M.A., Bedo, T., Roata, I.C. \& Luca, M.A. (2018). Calcium carbonate and wood reinforced hybrid PVC composites. J Appl Polym Sci, 135(22), 46317. DOI: https://doi.org/10.1002/app.46317.

4. Pulngern, T., Padyenchean, C., Rosarpitak, V., Prapruit, W. \& Sombatsompop, N. (2011). Flexural and creep strengthening for wood/PVC composite members using flat bar strips. Mater Des, 32(6), 3431-9. DOI: https://doi.org/10.1016/j.matdes.2011.02.005.

5. Sundstøl, F. \& Owen, E. (1984). Straw and Other Fibrous Byproducts as Feed. Elsevier Science Publishers B.V, Amsterdam/New York, 610pp.

6. Yao, F., Wu, Q., Lei, Y. \& Xu Y., (2008). Rice straw fiberreinforced high-density polyethylene composite: Effect of fiber type and loading. Ind Crops Prod, 28(1), 63-72. DOI: https://doi.org/ 10.1016/j.indcrop.2008.01.007.

7. Mindivan, F. \& M. Göktaş (2019). Preparation of new PVC composite using green reduced graphene oxide and its effects in thermal and mechanical properties. Polymer Bulletin, 2019, 1-21. DOI: https://doi.org/10.1007/s00289-019-02831-x.

8. Hummers, W.S. \& Offeman, R.E.(1958). Preparation of graphitic oxide. Journal of the American Chemical Society, 80, 1339. DOI: https://doi.org/10.1021/ja01539a017.

9. Mindivan, F. (2017). Effect of various initial concentrations of $\mathrm{CTAB}$ on the noncovalent modified graphene oxide (MGNO) structure and thermal stability. Materials Testing, 59( 9), 729-734. DOI: $10.3139 / 120.111063$

10. Fombuena, V. , Bernardi, L. , Fenollar, O. , Boronat, T. \& Balart, R. (2014). Characterization of green composites from biobased epoxy matrices and bio-fillers derived from seashell wastes. Materials and Design, 57, 168-174. DOI: https://doi.org/10.1016/j.matdes.2013.12.032.

11. Moustafa, H. Youssef, A.M. Duquesne, S. \& Darwish, N.A. (2015). Characterization of Bio-Filler Derived From Seashell Wastes and its Effect on the Mechanical, Thermal, and Flame Retardant Properties of ABS Composites. Polymer Composites, 38, 27882797. DOI: https://doi.org/10.1002/pc.23878.

12. Sonawane, S.H, Shirsath, S.R., Khanna, P.K., Pawar, S., Mahajan, C.M. Paithankar, V., Shinde,. V. \& Kapadnis, C.V. (2008). An innovative method for effective micro-mixing of $\mathrm{CO}_{2}$ gas during synthesis of nano-calcite crystal using sonochemical carbonization. Chem. Eng. J., 143, 308-313. DOI: https://doi.org/10.1016/j.cej.2008.05.030.

13. Donnelly, F.C., Purcell-Milton, F., Framont, V., Cleary, O., Dunne, P.W. \& Gun'ko, Y.K. (2017). Synthesis of $\mathrm{CaCO}_{3}$ nanoand micro-particles by dry ice carbonation. Chem. Commun., 53, 6657-6660. DOI: https://doi.org/10.1039/C7CC01420A.

14. Gunasekaran, S., Anbalagan, G. \& Pandi S. (2006). Raman and infrared spectra of carbonates of calcite structure. J. Raman Spectrosc., 37, 892-899. DOI: https://doi.org/10.1002/jrs.1518.

15. Price, G., Mahon, M., Shannon, J. \& Cooper, C. (2011). Composition of calcium carbonate polymorphs precipitated using ultrasound. Cryst. Growth Des.,11, 39-44. DOI: https://doi.org/10.1021/cg901240n.
16. Ma, Y. \& Feng, Q. (2011). Alginate hydrogel-mediated crystallization of calcium carbonate J. Solid State Chem., 184, 1008-1015. DOI:https://doi.org/10.1016/j.jssc.2011.03.008.

17. Mart1'nez-Garc1'a, C., Gonza'lez-Fonteboa, B., Martı'nez-Abella, F. \&. Carro- Lo'pez, D. (2017). Performance of mussel shell as aggregate in plain concrete. Constr. Build. Mater., 139, 570583.DOI:https://doi.org/10.1016/j.conbuildmat.2016.09.091.

18. Boronat, C., Correcher, V., Virgos, M.D., \& Garcia-Guinea, J. (2017). Ionising radiation effect on the luminescence emission of inorganic and biogenic calcium carbonates. Nuclear Instruments and Methods in Physics Research B, 401, 1-7. DOI:http://dx.doi.org/10.1016/j.nimb.2017.04.035.

19. Islam, K.N., Bin Abu Bakar, M.Z., Ali, M.E, Bin Hussein, M.Z., Noordin, M.M., Loqman, M.Y. Miah, G., Wahid, H. \& Hashim, U. (2013). A novel method for the synthesis of calcium carbonate (aragonite) nanoparticles from cockle shells. Powder Technology, 235, 70-75. DOI:https://doi.org/10.1016/j.powtec.2012.09.041

20. Romero, A., Lavin-Lopez, M.P., Sanchez Silva, L., Valverde, J.L. \& Paton-Carrero, A. (2018). Comparative study of different scalable routes to synthesize graphene oxide and reduced graphene oxide. Materials Chemistry and Physics, 203, 284-292. DOI: https://doi.org/10.1016/j.matchemphys.2017.10.013

21. Chowdhury, S. \& Balasubramanian, R. (2014). Recent advances in the use of graphene-family nanoadsorbents for removal of toxic pollutants from wastewater. Advances in Colloid and Interface Science, 204, 35-56. DOI: https://doi.org/10.1016/j.cis.2013.12.005

22. Sharma, S. , Susan, D., Kothiyal, N.C. \& Kaur, R. (2018). Graphene oxide prepared from mechanically milled graphite: effect on strength of novel fly-ash based cementitious matrix. Constr. Build. Mater. 177, 10-22. DOI:https://doi.org/10.1016/j.conbuildmat.2018.05.051.

23. Lv, S., Ting, S., Liu, J., \& Q., Zhou (2014). Use of graphene oxide nanosheets to regulate the microstructure of hardened cement paste to increase its strength and toughness. Cryst. Eng. Comm., 16, 8508-8516. DOI: https://doi.org/10.1039/c4ce00684d.

24. Amangah, M. , Salami-Kalajahi, M. \& Roghani-Mamaqani, H. (2018). Nanoconfinement effect of graphene on thermophysical properties and crystallinity of matrix-grafted graphene/crosslinked polysulfide polymer nanocomposites. Diamond and Related Materials, $\quad 83, \quad 177-183 . \quad$ DOI: https://doi.org/10.1016/i.diamond.2018.02.012.

25. Mindivan, F. (2015). The Synthesis, Thermal And Structural Characterization of Polyvinylchloride/Graphene Oxide (PVC/GO) Composites. International Scientific Journal "Materials Science. Non-Equilıbrum Phase Transformatıons", 3, 33-36.

26. Lakshmanna, B., Jayaraju, N., Lakshmi Prasad, T., Sreenivasulu, G., Nagalakshmi, K., Pramod Kumar, M., \& Madakka, M. (2018). Data on Molluscan Shells in parts of Nellore Coast, southeast coast of India. Data in Brief , 16, 705-712. DOI: https://doi.org/10.1016/j.dib.2017.11.081.

27. Islam, K.N., Bin Abu Bakar, M.Z., Ali, M.E., Bin Hussein, M. Z., Noordin, M.M., Loqman, M.Y., Miah, G., Wahid, H. \& Hashim, U. (2013). A novel method for the synthesis of calcium carbonate (aragonite) nanoparticles from cockle shells. Powder Technology, 235, 70-75. DOI: https://doi.org/10.1016/j.powtec.2012.09.041.

28. Huang, J., Liu, C., Xie, L., \& Zhang, R. (2018). Amorphous calcium carbonate: A precursor phase for aragonite in shell disease of the pearl oyster. Biochemical and Biophysical Research $\begin{array}{llll}\text { Communications, } & 497, & 102-107 . & \text { DOI: }\end{array}$ https://doi.org/10.1016/j.bbrc.2018.02.031.

29. Zhou, G.-T., Yao, Q.-Z., Ni, J., \& Jin, G. (2009). Formation of aragonite mesocrystals and implication for biomineralization. American Mineralogist, 94, 293-302. DOI: https://doi.org/10.2138/am.2009.2957.

30. Hoque, M.E., Shehryar, M. \& Islam, K.N.(2013). Processing and Characterization of Cockle Shell Calcium Carbonate $\left(\mathrm{CaCO}_{3}\right)$ Bioceramic for Potential Application in Bone Tissue Engineering. Journal of Material Sciences \& Engineering, 2, 1-5. DOI: 10.4172/2169-0022.1000132. 